\title{
The antimicrobial effect of wine on Listeria innocua in a model stomach system
}

\author{
João Fernandes ${ }^{1}$, Francisco Gomes ${ }^{1}$, José António Couto *, Tim Hogg \\ Escola Superior de Biotecnologia, Universidade Católica Portuguesa, Rua Dr. António Bernardino de Almeida, 4200-072 Porto, Portugal
}

Keywords: Listeria; Wine; Cell inactivation

\begin{abstract}
A model stomach, containing a food matrix and a synthetic gastric fluid, was used to study the bactericidal effect of ingested wine on Listeria innосиа. Volumes of wine equivalent to the ingestion of one glass and half a bottle, led, over a period of less than $2 \mathrm{~h}$, to a reduction of 3 and 4 logarithmic cycles of the initial population respectively. The influence of ethanol and organic acids, wine constituents with known antimicrobial properties, was investigated. Ethanol exhibited a higher bactericidal effect than the mixture of the main wine organic acids. When testing the organic acids separately, malic and lactic acids were found to have the strongest effect. The combination of ethanol with the organic acids acted synergistically but to a lesser extent than wine itself. The results suggest that the ingestion of wine during a meal may diminish the quantity of Listeria persisting further in the alimentary tract.
\end{abstract}

\section{Introduction}

The consumption of wine has been reported to have a protective effect, as regards the propensity to develop bacterial food poisoning. (Belido-Blasco et al., 2002). Evidence exists that individuals who ingest wine during a meal become less susceptible to food-borne toxi-infections (Correia et al., 2003). Weisse, Eberly, and Person (1995) demonstrated that wine was able to reduce the viability of Salmonella enteritidis, Shigella sonnei and Escherichia coli by $5-6 \log$ cycles in $20 \mathrm{~min}$. Similar inactivation figures were obtained by Sugita-Konishi, Hara-Kudo, Iwamoto, and Kondo (2001) for S. enteritidis, E. coli O157:H7 and Vibrio parahaemolyticus. The consumption of alcoholic beverages was described as having a protective effect against infections of Helycobacter pylori (Luzza, Imeneo, Maletta, \& Pallone, 1998). More recently, Møretrø and Daeschel (2004) have shown that wine has bactericidal activity against E. coli,

\footnotetext{
Corresponding author.

E-mail address: jacouto@esb.ucp.pt (J.A. Couto).

${ }^{1}$ These authors have contributed equally to this article
}

Listeria monocytogenes, Salmonella typhimurium and Staphylococcus aureus. The exact mechanisms responsible for the antimicrobial effect of wine are, however, not fully understood. Wine is a beverage with some unique characteristics. It possesses a relatively high ethanol content in addition to other antimicrobial agents like organic acids, low $\mathrm{pH}$, polyphenol compounds and preservatives (Just \& Daeschel, 2003). The antimicrobial activity of wine has been under investigation by some researchers, however, most of these studies employed experimental conditions quite distant from in vivo conditions, most using mixtures of wine and a low $\mathrm{pH}$ solution to effect the inactivation, certainly food material was rarely included.

With a $\mathrm{pH}$ value of between 1 and 3 , the stomach is a hostile environment for most bacteria (Maltby, Lewis, Martin, \& Sunderland, 1991). The importance of the gastric juice as a bactericidal barrier has been known for almost a century, being one of the first lines of defence (host unspecific immunity) against ingested pathogenic organisms (Tortora, Funke, \& Case, 1998). Although diverse antimicrobial components have been reported in the gastric juice $(\mathrm{HCl}$, pepsin, mucous), it has been already described, in 
some previous works, that the gastricidal activity of stomach is predominantly $\mathrm{pH}$ (chloridric acid) dependent (Just \& Daeschel, 2003).

Listeriosis is an atypical food-borne disease caused by bacteria of the genus Listeria. Its high importance and interest in terms of public health is due to its severity, as illustrated by the high rate of mortality $(20-30 \%)$ particularly affecting naturally immunosuppressed people (pregnant women, newly-born, old people) or during illness (cancer, cirrhosis, immunosuppressant treatment, etc.), and by the non-enteric nature of the illness (meningitis, septicaemia and abortion). Two determinative characteristics for its distribution in the a food chain are (i) its ability to grow at low (refrigeration) temperature and (ii) its relatively high resistance (particularly for a vegetative bacteria) to many environmental stresses. Thus, Listeria can contaminate the food in diverse steps of the food chain and resist storage at low temperatures (Doyle, Beuchat, \& Montville, 1997; Schlech et al., 1983; Steinhart, Doyle, \& Cochrane, 1995).

In this work, the bactericidal effect of wine on Listeria innocua (as a substitute for L. monocytogenes) in a food matrix, under simulated gastric conditions (stomach model), was studied. The specific influence of some wine components on this effect was also evaluated. L. innocua has been acknowledged as a safe non-pathogenic substitute for L. monocytogenes (Fairchild \& Foegeding, 1993; Piyasena, Liou, \& Mckellar, 1998), thus being used as a model organism in previous studies (Francis \& O'Beirne, 1998; Houtsma, Kusters, de Wit, Rombouts, \& Zwietering, 1994; Omary, Testin, Barefoot, \& Rusting, 1993).

\section{Materials and methods}

\section{Bacteria and culture conditions}

The strain L. innocua NCTC 11288 was used. The culture was preserved in slants of Tryptone Soy Agar (TSA) medium (Pronadisa, Madrid, Spain) with $6 \mathrm{~g} / \mathrm{L}$ of yeast extract (Lab M, Bury, UK) (TSA-YE) and kept at $4{ }^{\circ} \mathrm{C}$. For each assay, the inoculum was transferred from TSA-YE slants to $10 \mathrm{ml}$ of TSB-YE broth (Tryptone Soy Broth [Pronadisa] supplemented with $6 \mathrm{~g} / \mathrm{L}$ of yeast extract [Lab M]) and incubated at $37^{\circ} \mathrm{C}$ until the stationary phase was reached $( \pm 16 h)$.

\section{Wines, organic acids and ethanol}

One red wine and one white wine from the Douro demarcated region (Portugal) were used. The ethanol concentration of both wines was $12.5 \%(\mathrm{v} / \mathrm{v})$. These were filter sterilized using $0.45 \mu \mathrm{m}$ cellulose acetate membranes (Orange Scientific of GyroDisc, CA) and were kept at $4{ }^{\circ} \mathrm{C}$, in sterile bottles of $200 \mathrm{~mL}$, until used. The $\mathrm{pH}$ of the wines was determined by potentiometry using a Crison micro $\mathrm{pH}$ 2002 (Crison Instruments SA, Barcelona, Spain) pH meter. The total and free sulphur dioxide $\left(\mathrm{SO}_{2}\right)$ concentrations, the total acidity and the volatile acidity were determined by the standard methods recommended by the organisation internationale de la vigne et du vin (OIV).

Filter sterilised solutions of the main wine organic acids were prepared and, in the appropriate experiments, were mixed to obtain the final following concentrations in the model stomach: $4 \mathrm{~g} / \mathrm{L}$ of tartaric acid (Merck, Dramstad, Germany), $0.1 \mathrm{~g} / \mathrm{L}$ of malic acid (Merck), $0.5 \mathrm{~g} / \mathrm{L}$ of acetic acid (Pronalab, Lisbon, Portugal), $1.5 \mathrm{~g} / \mathrm{L}$ of lactic acid (Sigma-Aldrich, Steinheim, Germany) and $0.5 \mathrm{~g} / \mathrm{L}$ of citric acid (Merck). Combinations of organic acids (at the same concentrations of those of the individuals) with or without ethanol were also tested.

\section{Elaboration of the stomach model}

In order to investigate the bactericidal effect of wine (or wine components) during a meal, a stomach model was developed having as base chemical factors the $\mathrm{pH}$ value, the volume of the gastric juice and the time of permanence of the food in the stomach. Commercially available sterile homogeneous chicken baby meals (Blédina) were used as food matrix. The gastric juice was simulated by adjusting the $\mathrm{pH}$ to 2 with $\mathrm{HCl}(1 \mathrm{M})$. The proportion of $400 \mathrm{~mL}$ of acid solution to $300 \mathrm{~g}$ of solid meal was used (Malagelada, 1977). One-thirty milliliters of simulated gastric juice was added to $100 \mathrm{~g}$ of food. The effect of the gastric protease pepsin was evaluated. A digestion time of $2 \mathrm{~h}$ was assumed.

\section{Survival of bacteria in the stomach model}

Stationary phase cultures of L. innocua NCTC 11288 grown in TSB-YE for $16 \mathrm{~h}$ at $37^{\circ} \mathrm{C}$ were used in the survival experiments. For each assay, $500 \mathrm{ml}$ Erlenmeyer flasks with $100 \mathrm{~g}$ of food matrix were immersed and magnetically stirred in a thermostatted water bath (Tectrom 3473100, Selecta, Spain) at $37^{\circ} \mathrm{C}$. After stabilisation of the temperature, a $1 \%$ inoculum $(2.3 \mathrm{~mL}$ in $230 \mathrm{~mL}$ of final volume) was transferred to the Erlenmeyers. The liquid test, either deionised water, wine, organic acid(s), ethanol or the diverse combinations, prewarmed to $37^{\circ} \mathrm{C}$, together with the necessary amount of $\mathrm{HCl}$ in order not to modify the $\mathrm{pH}$ of the stomach model, was then added. Samples were collected at different times (maximum of $120 \mathrm{~min}$ ), properly diluted and plated on TSA-YE medium by the technique of Miles and Misra (1938). Plates were incubated at $37^{\circ} \mathrm{C}$ during 24-36 h.

Survival at any given time point was determined as the ratio colony forming units (CFU) after treatment to the number of CFU at the zero time point. Means of 2 or 3 replicates with standard error bars are shown in the graphs.

\section{Results}

The effect of the addition of different amounts of red wine on the survival of $\mathrm{L}$. innocua in the stomach model

$L$. innocua was chosen as a nonpathogenic model organism for $L$. monocytogenes. The suitability of $L$. innocua as a 


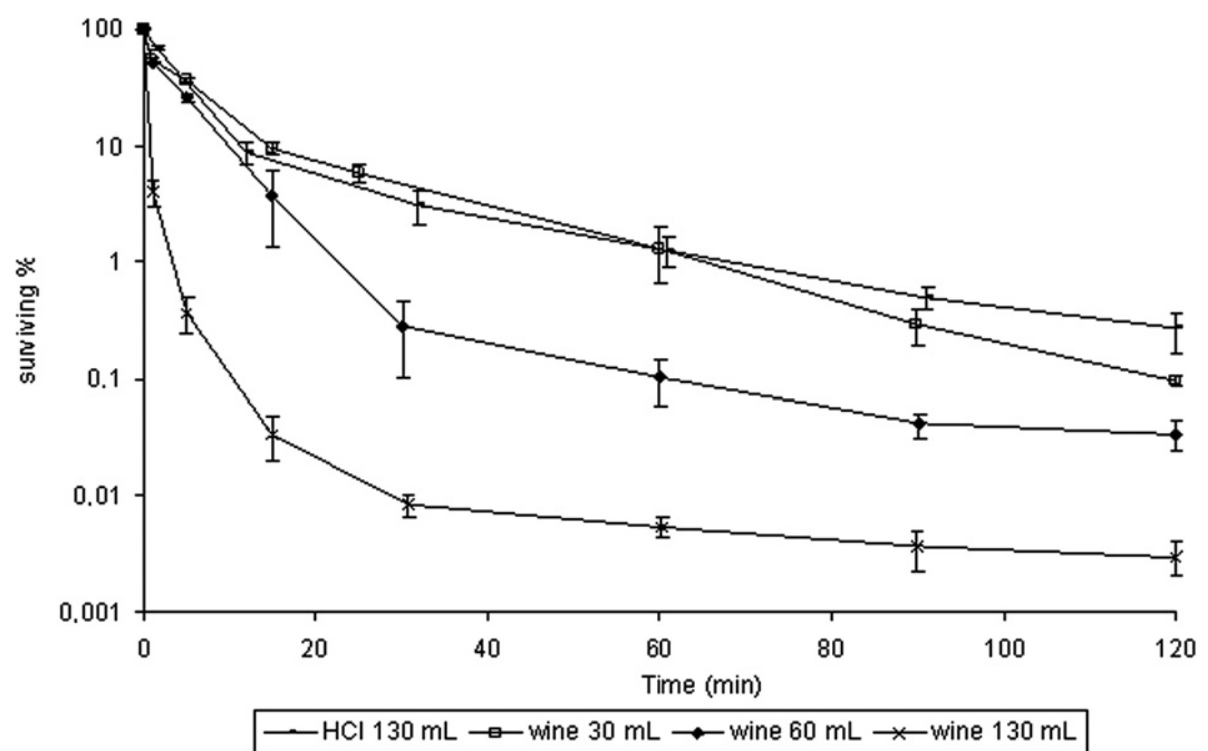

Fig. 1. Effect of the addition of different amounts of red wine on the survival of Listeria innocua NCTC 11288 in the stomach model. Each point represents the average value of three determinations; bars represent the standard error.

substitute for L. monocytogenes is based on the fact that it has been shown that both species behave in a similar manner when submitted to several different types of environmental stresses (García-Graells, Valckx, \& Michiels, 2000; Piyasena et al., 1998). In order to determine the influence of a red wine (total acidity of $5.9 \mathrm{~g} / \mathrm{L}$, volatile acidity of $0.64 \mathrm{~g} /$ $\mathrm{L}$ and $\mathrm{pH} 3.59$ ) on the survival of $L$. innocua NCTC 11288 during a simulated meal in a stomach model, assays were made with the addition of $30 \mathrm{~mL}, 60 \mathrm{~mL}$ and $130 \mathrm{~mL}$ of wine which, proportionally to the amount of food in the stomach model, correspond, approximately, to half a glass, a glass and half a bottle, respectively.

Fig. 1 demonstrates that the synthetic gastric fluid (SGF) was responsible for a decrease in cell viability of $2 \log$ cycles in $120 \mathrm{~min}$. It can also be seen that the presence of wine led to a substantial additional cell inactivation. The higher the amount of added wine the higher the inactivation of the bacteria. The effect of the addition of $30 \mathrm{~mL}$ is similar to the control (SGF), except at the time point of $120 \mathrm{~min}$ of exposition. The addition of 60 or $130 \mathrm{~mL}$ shows a higher inhibitory effect, specially noted in the first $30 \mathrm{~min}$. When compared with the control assay, the application of these quantities of wine led to an additional reduction of 1 and $2 \log$ cycles, respectively. After the accentuated decrease of cell survival in the first $30 \mathrm{~min}$, the curve tends to stabilise, which can be explained by the presence of a non-homogeneous population in terms of resistance to the factors under study.

An assay was carried out in which the wine was added 60 min after the inoculation of the stomach model, in order to verify if $L$. innocua is able to develop some kind of resistance, in the period before the cell contact with wine. The effect obtained (Fig. 2) was found to be similar to that observed when wine is added from the beginning of the experiment, thus not being evident the acquisition of any type of bacterial resistance. Until the minute 60 , in which the bacteria is mainly subjected to the effect of $\mathrm{pH} \mathrm{2,} \mathrm{the}$ inactivation is low and identical to the assays without wine seen in Fig. 1. When wine is added, a rapid decrease (in $2 \mathrm{~min}$ ) in the cell survival is verified. The inactivation proceeds until 4 or $5 \log$ cycles reduction is obtained depending on the amount of wine used.

\section{Determination of the main bactericidal components of the wine}

The exact mechanisms responsible for the antimicrobial effect exhibited by wine are not fully understood, as the wine possesses diverse components that are known to have antimicrobial activity. Since ethanol and organic acids are among the main bactericidal elements in wine, the influence of these compounds was tested. The main organic acids tartaric, acetic, lactic, malic and citric acids (Jackson, 2000) - and mixtures of the acids with and without ethanol (at similar concentrations present in wines) were used. The effect of sulphur dioxide was not tested because the concentration of this compound on the tested wines, after the sterilisation, was found to be relatively low $(11$ and $5 \mathrm{mg} / \mathrm{L}$ of free $\mathrm{SO}_{2}$ on red and white wine, respectively). The inactivation with $130 \mathrm{~mL}$ of red wine was taken as control assay. The ethanol and the mixture of organic acids provoked similar kinetics of inactivation (Fig. 3). In the first $20 \mathrm{~min}$ only a slight decrease in cell survival is observed, a higher effect being noted from that time on. The combination of the acids with ethanol showed a higher bactericidal effect than the mixture of acids and ethanol in separate, thus approximating to the effect obtained with wine, specially from $90 \mathrm{~min}$ on. Møretrø and Daeschel (2004), although not using a model stomach system, also found a high rate of inactivation when cells of $L$. monocytogenes were exposed 


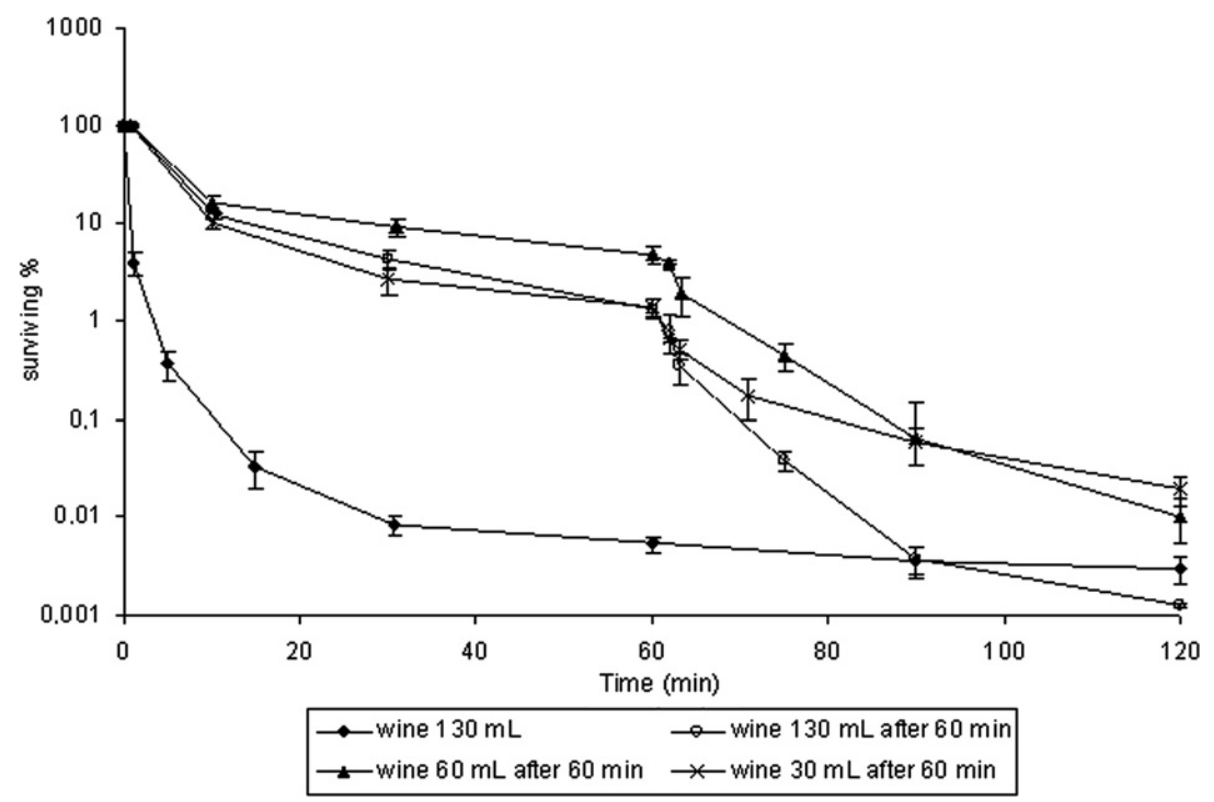

Fig. 2. Effect of the addition of different amounts of wine $60 \mathrm{~min}$ after the inoculation of the stomach model with Listeria innocua NCTC 11288 . The inactivation curve obtained from the addition of $130 \mathrm{~mL}$ of wine at time 0 is used as control. Each point represents the average value of three determinations; bars represent the standard error.

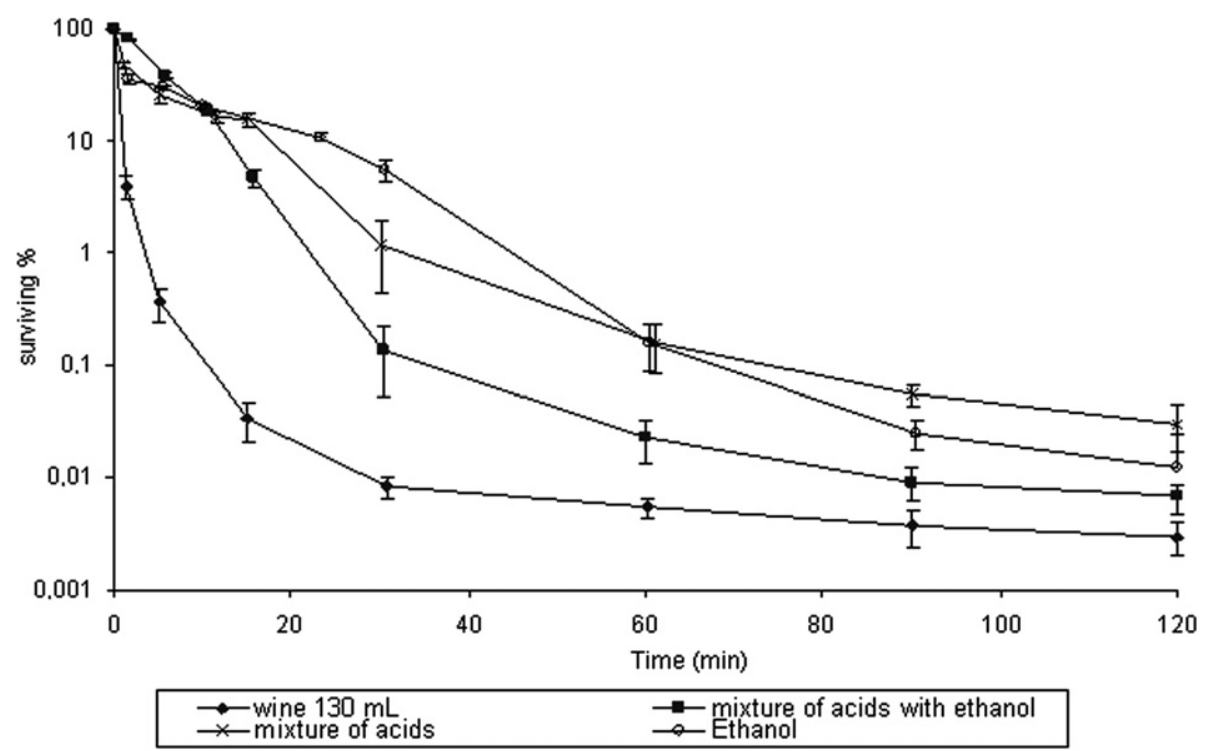

Fig. 3. Effect of the addition of a mixture of organic acids $(4 \mathrm{~g} / \mathrm{L}$ tartaric, $0.1 \mathrm{~g} / \mathrm{L}$ malic, $0.5 \mathrm{~g} / \mathrm{L}$ acetic, $1.5 \mathrm{~g} / \mathrm{L}$ lactic and $0.5 \mathrm{~g} / \mathrm{L}$ citric), with and without ethanol $(12.5 \% \mathrm{v} / \mathrm{v})$, in comparison with the addition of ethanol on the survival of Listeria innocua NCTC 11288. The inactivation curve obtained from the addition of $130 \mathrm{~mL}$ of wine is used as control. Each point represents the average value of three determinations; bars represent the standard error.

to $15 \%(\mathrm{v} / \mathrm{v})$ ethanol at $\mathrm{pH} 3$. In the same work, the combination of tartaric acid $(6 \mathrm{~g} / \mathrm{L})$, malic acid $(1.5 \mathrm{~g} / \mathrm{L})$ and $10 \%$ $(\mathrm{v} / \mathrm{v})$ ethanol also led to a strong reduction in cellviability. Just and Daeschel (2003) found that the non-volatile wine fraction (containing acids) was more effective in the inactivation of Salmonella than the volatile fraction (containing alcohol).

The effect of the organic acids was studied individually at the same concentrations used in the mixture. As seen in Fig. 4 , tartaric acid $(4 \mathrm{~g} / \mathrm{L})$ and citric acid $(0.5 \mathrm{~g} / \mathrm{L})$ caused a
1 log cycle survival reduction while acetic acid $(0.5 \mathrm{~g} / \mathrm{L})$ was responsible for a $2 \log$ cycles reduction. Malic acid, even at a relatively low concentration $(0.1 \mathrm{~g} / \mathrm{L})$ and lactic acid $(1.5 \mathrm{~g} / \mathrm{L})$ were found to be the most effective in the inactivation of L. innocua NCTC 11288 causing a 3-fold reduction, which is similar to what is caused by the mixture of the five acids without ethanol (Fig. 3). The effect of ethanol was found to be higher than any of the organic acids at the concentrations used (Fig.4). The higher bactericidal effect caused by malic and lactic acids, in comparison to the other 


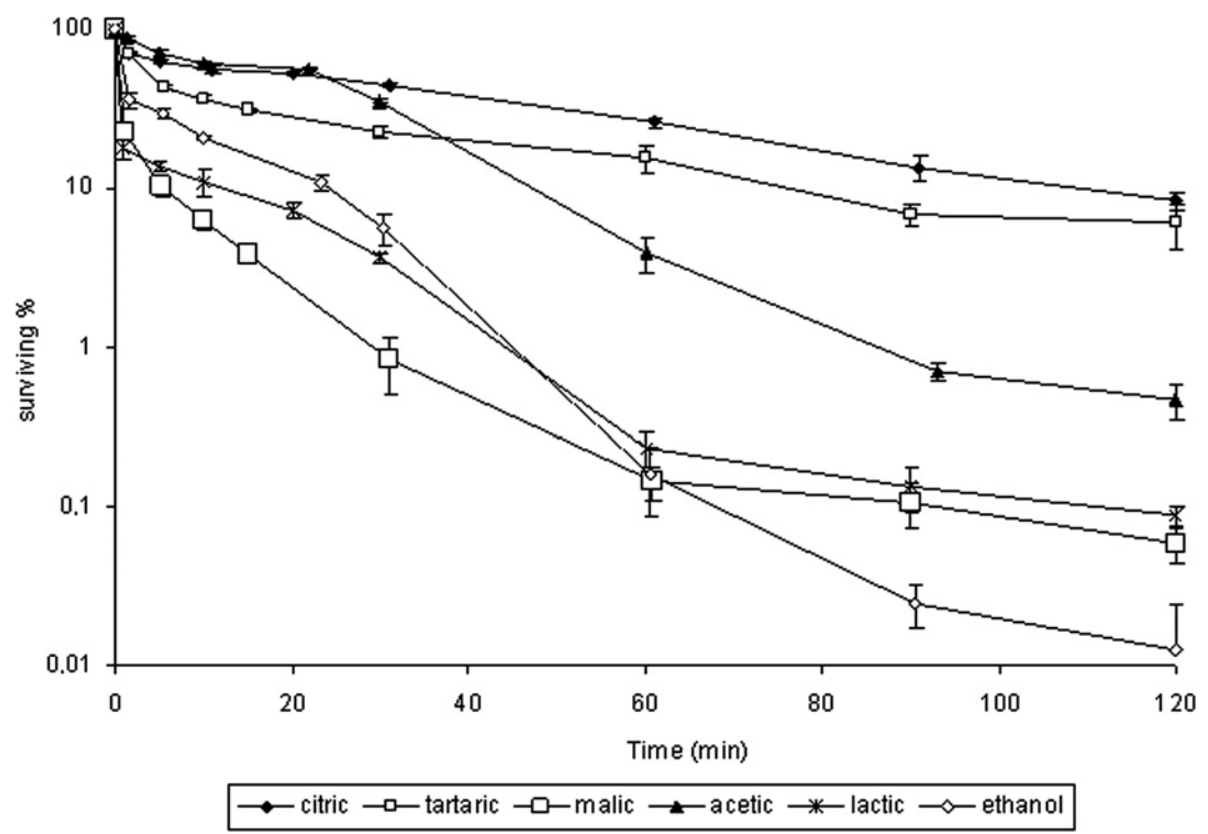

Fig. 4. Effect of the addition of organic acids and ethanol in separate on the survival of Listeria innocua NCTC 11288. Each point represents the average value of three determinations; bars represent the standard error.

acids, may be explained due the fact that, in the experimental conditions, these acids penetrate more easily inside the cell, dissociating on its interior and disturbing the gradient of protons between the two sides of the cell membrane.

By combining the two individual compounds which exhibit the highest bactericidal effect, ethanol and malic acid, it was possible to verify that the result of this association is identical to that of the mixture of the five organic acids plus ethanol (Fig. 5). So that, it can be assumed that the antimicrobial effect of the organic acids fraction is mainly due to malic and lactic acids. It is important to note that there is a difference between the effect of the mixture of the organic acids with ethanol and the effect of wine (Figs. 3 and 5), which indicate that other constituents (e.g. phenolic compounds), also contribute to the bactericidal effect of wine (Rhodes, Mitchell, Wilson, \& Melton, 2006).

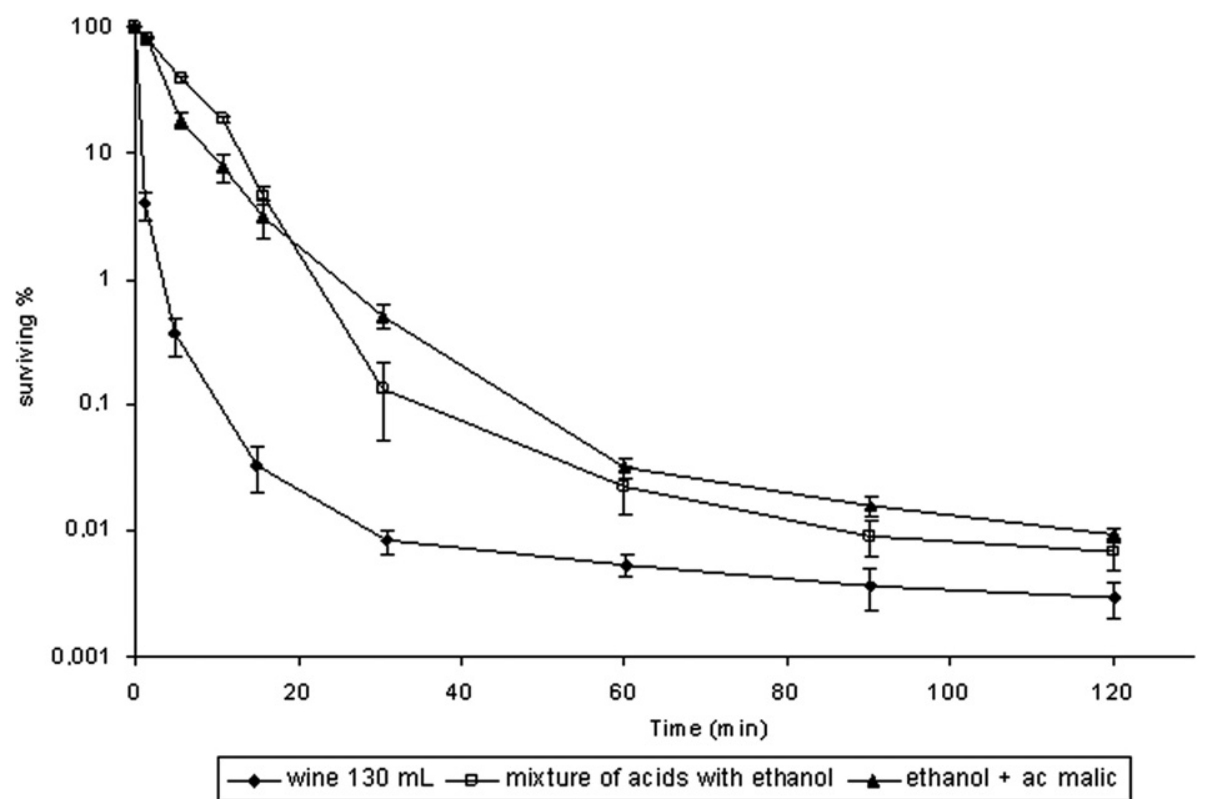

Fig. 5. Effect of the addition of the mixture of organic acids ( $4 \mathrm{~g} / \mathrm{L}$ tartaric, $0.1 \mathrm{~g} / \mathrm{L}$ malic, $0.5 \mathrm{~g} / \mathrm{L}$ acetic, $1.5 \mathrm{~g} / \mathrm{L}$ lactic and $0.5 \mathrm{~g} / \mathrm{L}$ citric) with ethanol (12.5\%) and malic acid $(0.1 \mathrm{~g} / \mathrm{L})$ with ethanol $(12.5 \%)$ on the survival of Listeria innocua NCTC 11288 . The inactivation curve obtained from the addition of $130 \mathrm{~mL}$ of wine is used as control. Each point represents the average value of three determinations; bars represent the standard error. 


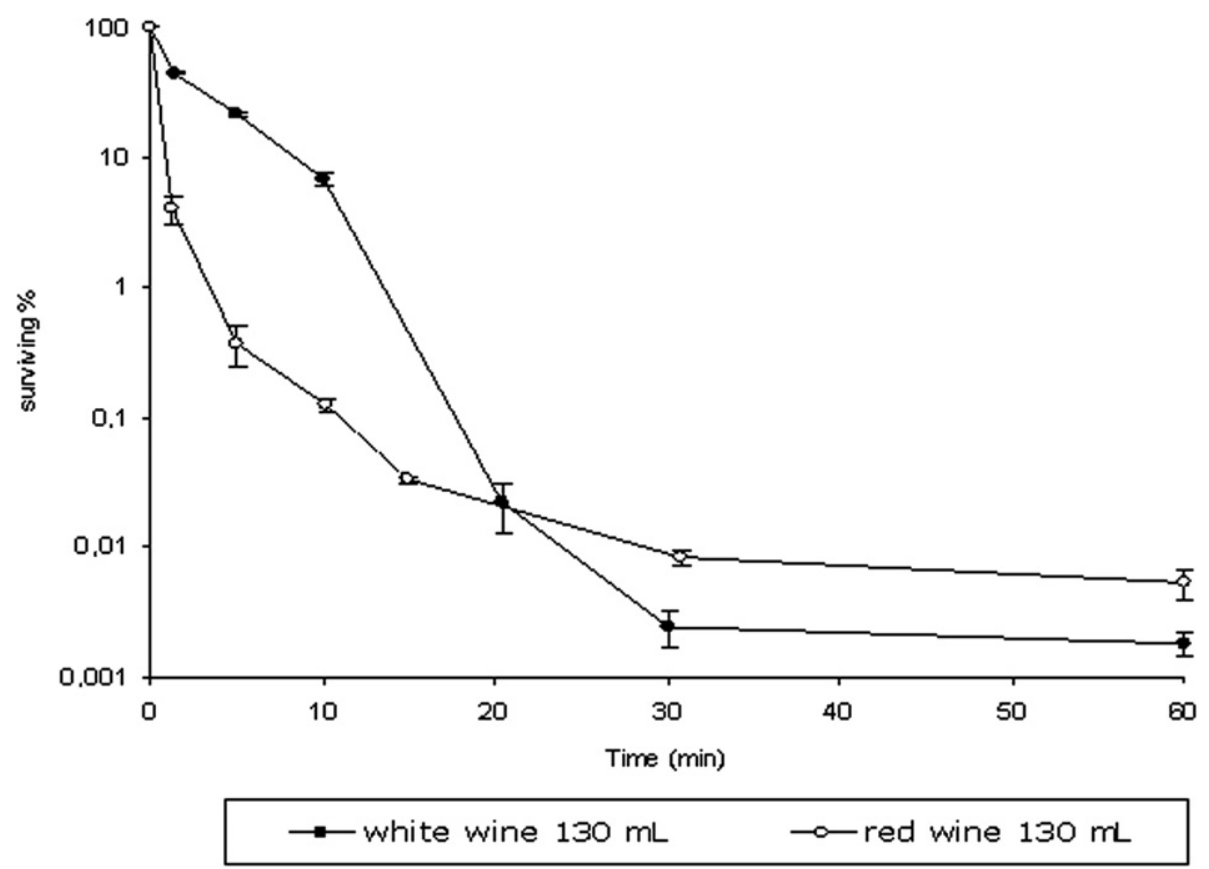

Fig. 6. Comparison of the bactericidal effect of a red wine and of a white wine on Listeria innocua NCTC 11288. Each point represents the average value of three determinations; bars represent the standard error.

\section{Comparison of the antimicrobial effects of white wine with red wine}

The effect of a white wine (total acidity of $5.7 \mathrm{~g} / \mathrm{L}$, volatile acidity of $0.49 \mathrm{~g} / \mathrm{L}, \mathrm{pH} 3.45$ ) was also tested. In comparison to the red wine it can be observed (Fig. 6) than the kinetics of inactivation is different. Although it shows a lighter effect in the beginning of the inactivation $(10 \mathrm{~min})$, at the end of the experimental time $(60 \mathrm{~min})$ a lower concentration of survivals is found in the case of using white wine. One possible explanation for this might be linked to the fact that the white wine used in this work did not undergo malolactic fermentation, thus possessing a higher concentration of malic acid than the red wine. This is in accordance with the findings of Just and Daeschel (2003) who noticed that Chardonnay wine and its non-volatile fraction were more lethal to Salmonella populations than the Pinot noir wine and its volatile fraction; but not with Møretrø and Daeschel (2004) who found the tested red wine to be more potent than the white wine in killing L. monocytogenes. In this case, the explanation was that the red wine had a higher ethanol content and titratable acidity than the white wine. It seems clear that the wine effectiveness in the inactivation of bacteria is strongly dependent on the specific wine composition.

\section{Discussion}

This is, to our knowledge, the first work which shows the effect of wine on Listeria in a model stomach system. The results presented demonstrate that wine may lead to a reduction of 4-5-folds of the initial population of
L. innocua in the acidic conditions tested (model stomach system). Considering that $L$. monocytogenes and $L$. innocua are phylogenetically close organisms and that are identical in most aspects except pathogenesis (Margolles, Mayo, \& de los Reyes-Gavilán, 2000; Murray et al., 1989), the ingestion of wine during a meal contaminated with $10^{6} / \mathrm{g}$ cells of L. monocytogenes, may cause a reduction in the bacterial population capable of preventing the occurrence of foodborne toxi-infections caused by this pathogenic bacteria. The exact infective dose of $L$. monocytogenes is unknown but is believed to vary with the strain and susceptibility of the individual. A concentration of 100 cells/g of food at the time of consumption is, however, considered a low risk to consumers (Forsythe, 2000). As pointed out by Just and Daeschel (2003), the human digestion is influenced by many factors, some of which were not considered in the model stomach system employed in this work, such as the peristaltic movement, the specific immune responses or the competition with natural microflora. It is, therefore, reasonable to think that the antimicrobial action of a in vivo digestion could be even stronger than under the conditions tested in this work.

\section{References}

Belido-Blasco, J. B., Arnedo-Pena, A., Cordero-Cutillas, E., Canos-Cabedo, M., Herrero-Carot, C., \& Safont-Adsuara, L. (2002). The protective effect of alcoholic beverages on the occurrence of a Salmonella food-borne outbreak. Epidemiology, 13, 228-230.

Correia, A., Gomes, A., Oliveira, B., Gonçalves, G., Miranda, M., \& Almeida, O. (2003). The protective effect of alcoholic beverages in foodborne outbreaks of Salmonella enteritidis PT1 in northern Portugal. Eurosurveillance Weekly, 7(13). 
Doyle, M. P., Beuchat, L. R., \& Montville, T. J. (1997). In M. P. Doyle, L. R. Beuchat, \& T. J. Montville (Eds.), Food Microbiology - Fundamentals and Frontiers (second ed., pp. 337-352). Washington DC: ASM Press.

Fairchild, T. M., \& Foegeding, P. M. (1993). A proposed non-pathogenic biological indicator for thermal inactivation of Listeria monocytogenes. Applied and Environmental Microbiology, 66, 1247-1250.

Forsythe, S. J. (2000). In S. J. Forsythe (Ed.), The Microbiology of Safe Food (pp. 335-347). United Kingdom: Blackwell Science.

Francis, G. A., \& O'Beirne, D. (1998). Effects of the indigenous microflora of minimally processed lettuce on the survival and growth of Listeria innocua. International Journal of Food Science and Technology, 33, 477488.

García-Graells, C., Valckx, C., \& Michiels, C. W. (2000). Inactivation of Escherichia coli and Listeria innocua in Milk by Combined Treatment with High Hydrostatic Pressure and the Lactoperoxidase System. Applied Environmental Microbiology, 66, 4173-4179.

Houtsma, P. C., Kusters, B. J. M., de Wit, J. C., Rombouts, F. M., \& Zwietering, M. H. (1994). Modelling rates of Listeria innocuaas a function of lactacte concentration. International Journal of Food Microbiology, 24, $113-123$.

Jackson, R. S. (2000). Wine Science: Principles, Practice, Perception. New York, NY, USA: Academic Press.

Just, J. R., \& Daeschel, M. A. (2003). Antimicrobial effects of wine on Escherichia coli O157:H7 and Salmonella typhimurium in a stomach model system. Journal of Food Science, 68, 285-290.

Luzza, F., Imeneo, M., Maletta, M., \& Pallone, F. (1998). Smoking, alcohol and coffee consumption, and $H$. pylori infection. Alcohol consumption eliminates rather than prevents infection with H. pylori. British Medical Journal, 316, 1019.

Malagelada, J.-R. (1977). Quantification of gastric solid-liquid medium discrimination during digestion of ordinary meals. Gastroenterology, $72,1264-1267$.

Maltby, J. R., Lewis, P., Martin, A., \& Sunderland, L. R. (1991). Gastric fluid volume and $\mathrm{pH}$ in elective patients following unrestricted oral fluid until $3 \mathrm{~h}$ before surgery. Canadian Journal of Anaesthesia, 38, 425-429.
Margolles, A., Mayo, B., \& de los Reyes-Gavilán, C. G. (2000). Phenotypic characterization of Listeria monocytogenes and Listeria innocua strains isolated from short-ripened cheeses. Food Microbiology, 17, 461-467.

Miles, A. A., \& Misra, S. S. (1938). The estimation of the bactericidal power of blood. Journal of Hygiene, 38, 732-749.

Møretrø, T., \& Daeschel, M. (2004). Wine is bactericidal to foodborne pathogens. Journal of Food Science, 69, 251-257.

Murray, R., Brenner, D., Holt, J., Krieg, N., Moulder, J., Pfennig, N., et al. (1989). Bergey's Manual of Systematic Bacteriology(Vol. 2). Baltimore, MD, USA: Williams \& Wilkins.

Omary, M. B., Testin, R. F., Barefoot, S. F., \& Rusting, J. W. (1993). Packaging effects on growth of Listeria innocua in shredded cabbage. Journal of Food Science, 58, 623-626.

Piyasena, P., Liou, S., \& Mckellar, R. C. (1998). Predictive modelling of inactivation of Listeria spp. in bovine milk during high-temperature short-time pasteurization. International Journal of Food Microbiology, 39, 167-173.

Rhodes, P. L., Mitchell, J. W., Wilson, M. W., \& Melton, L. D. (2006). Antilisterial activity of grape juice and grape extracts derived from Vitis vinifera variety Ribier. International Journal of Food Microbiology, 107, 281-286.

Schlech, W. F., 3rd., Lavigne, P. M., Bortolussi, R. A., Allen, A. C., Haldane, E. V., Wort, A. J., et al. (1983). Epidemic listeriosis evidence for transmission by food. The New England Journal of Medicine, 308, $203-$ 206.

Steinhart, C. E., Doyle, M. E., \& Cochrane, B. A. (1995). Food Safety 1995. New York, NY, USA: Marcel Dekker, Inc. pp. 486-506.

Sugita-Konishi, Y., Hara-Kudo, Y., Iwamoto, T., \& Kondo, K. (2001). Wine has activity against entero-pathogenic bacteria in vitro but not in vivo. Bioscience Biotechnology and Biochemistry, 65, 954-957.

Tortora, G. J., Funke, B. R. \& Case, C. L. (1998). Microbiologia (6th ed.), (pp. 440-460). Brazil: Artmed Editora.

Weisse, M. E., Eberly, B., \& Person, D. A. (1995). Wine as a digestive aid: comparative antimicrobial effects of bismuth salicylate and red and white wine. British Medical Journal, 311, 1657-1660. 